\title{
Boron Intake and decreased risk of mortality in kidney transplant recipients
}

\author{
Daan Kremer ${ }^{1}$ (1) Adrian Post $^{1}$. Ulrike Seidel ${ }^{2}$. Patricia Huebbe ${ }^{2}$. Yvonne van der Veen ${ }^{1}$. Dion Groothof ${ }^{1}$. \\ António W. Gomes-Neto ${ }^{1}$. Tim J. Knobbe ${ }^{1} \cdot$ Kai Lüersen $^{2} \cdot$ Michele F. Eisenga $^{1} \cdot$ Gerjan J. Navis ${ }^{1} \cdot$ Gerald Rimbach $^{2}$. \\ Stephan J. L. Bakker ${ }^{1} \cdot$ TransplantLines Investigators $^{3}$
}

Received: 18 May 2021 / Accepted: 6 October 2021 / Published online: 22 October 2021

(c) The Author(s) 2021

\begin{abstract}
Purpose In a search for potentially modifiable factors to improve long-term outcome among kidney transplant recipients (KTR), we hypothesized that boron exposure is associated with improved long-term outcome in KTR.

Methods We determined $24 \mathrm{~h}$ urinary boron excretion using inductively coupled plasma mass spectrometry as a measure of boron exposure in 693 stable KTR (57\% male, mean age 53y), enrolled in the TransplantLines Food and Nutrition Biobank and Cohort Study. Dietary intake was assessed using validated food-frequency questionnaires.

Results Linear regression analyses showed that dietary intake of fruit, wine and nuts were key determinants of boron excretion. In addition, boron excretion was negatively correlated with homocysteine and inflammatory parameters. In total, 73 (32\%), 47 (20\%) and 30 (13\%) KTR died among the lowest, middle and highest tertiles of $24 \mathrm{~h}$ urinary boron excretion, respectively $\left(P_{\text {log-rank }}<0.001\right)$. Cox regression analyses showed that high boron excretion was strongly associated with lower risk of mortality, independent of age, sex, estimated glomerular filtration rate and history of cardiovascular disease (HR per doubling: $0.51,95 \%$ CI: 0.40 to $0.66, P<0.001$ ).

Conclusion Boron may be an overlooked target to improve long-term survival among KTR and potentially other patients, likely through pathways other than inflammation or the methionine-homocysteine cycle that were previously suggested. Interventional trials are warranted to confirm the potential of dietary boron supplementation in KTR and other patient populations.
\end{abstract}

Keywords Blue Zones $\cdot$ Mediterranean diet $\cdot$ Trace elements $\cdot$ Wine intake $\cdot$ Transplantation $\cdot$ Inflammation

$\begin{array}{ll}\text { Abbreviations } \\ \text { 95\% CI } & 95 \% \text { Confidence interval } \\ \text { eGFR } & \text { Estimated glomerular filtration rate } \\ \text { HR } & \text { Hazard ratio } \\ \text { hs-CRP } & \text { High-sensitivity C-reactive protein }\end{array}$

The TransplantLines Investigators are listed under Acknowledgements section.

Daan Kremer

d.kremer@umcg.nl

1 Department of Internal Medicine, Division of Nephrology, University Medical Center Groningen and University of Groningen, Post Box 30.001, 9700 RB Groningen, The Netherlands

2 Institute of Human Nutrition and Food Science, University of Kiel, Kiel, Germany

3 UMC Groningen Transplant Center, University Medical Center Groningen and University of Groningen, Post Box 30.001, 9700 RB Groningen, The Netherlands
ICP-MS Inductively coupled plasma mass spectrometry

IQR Interquartile range

KTR Kidney transplant recipients

\section{Introduction}

Even after successful transplantation, kidney transplant recipients (KTR) remain a vulnerable patient group at increased risk of premature mortality [1]. The high mortality risk in KTR is associated with several well-established risk factors, such as hypertension and diabetes, but despite the fact that proper management of these risk factors is in the current treatment guidelines, long-term prognosis has hardly improved over the past decades [1]. This warrants a search for additional, hitherto unknown factors that may be associated with mortality in this vulnerable patient group. In this search, we studied dietary factors in the Blue Zones: regions of the world where a higher than a usual number of 
people live for more than 100 years, and have a low prevalence of chronic diseases. These regions include Sardinia (Italy), the islands of Okinawa (Japan), Loma Linda (California), Nicoya Peninsula (Costa Rica) and Ikaria (Greece) [2]. We set out to find common factors that may explain the exceptional longevity and physical and cognitive health of the elderly in these zones. One of these factors may be boron exposure.

Boron is a metalloid trace element with atomic number 5 , that occurs naturally in the form of boric acid, borax, and several other boron hydrates [3]. Notably, all Blue Zones are either near great boron reserves or near boron-rich oceans $[3,4]$, and the dietary patterns that are common in the Blue Zones are also high in boron, as they generally include generous amounts of fruits, nuts, vegetables and legumes [2, 5, 6]. Additionally, all Blue Zones are known for high intake of specific boron-rich foods, such as soy products (Loma Linda, Okinawa), beans (Nicoya, Ikaria), and wine (Sardinia) $[2,5,6]$. Given the long average lifespan and the low rates of cardiovascular disease in the boron-rich Blue Zones, we hypothesized that relatively high boron exposure may be associated with low rates of long-term mortality among KTR.

Boron-containing substances have been used by humans for millennia, mainly because of their antiseptic and preservative properties. For example, the Egyptians used boron as a mummification agent, and sodium borate and boric acid were widely used as a food preservative in the past centuries [3]. Potential physiological functions of boron in animals were first recognized in the 1980s, when studies indicated the necessity of boron in bone health and reproduction in zebrafish, chicks, mice, and rats [7-11]. More recent animal and human studies suggest potential beneficial effects of boron in numerous processes throughout the body [12-14]. Our hypothesis that boron exposure may improve patient survival is further supported by a study showing that supplementation of low amounts of boron increased life span in Drosophila (i.e. fruit fly) [15]. Additionally, human studies have suggested that boron beneficially affects the cardiovascular system, bone and brain health, and that boron exposure may be associated with a lower risk of cancer and premature mortality [14, 16-18]. Although exact physiological functions remain unclear, boron may exert beneficial effects as a result of anti-inflammatory properties or through the promotion of flux through the homocysteine-methionine cycle $[16,19-21]$. In light of these considerations, it may be interesting to not only investigate associations of $24 \mathrm{~h}$ urinary boron excretion with dietary intake, but also with clinical and biochemical parameters, including blood pressure, kidney function, circulating lipid concentrations, homocysteine and circulating concentrations of vitamins involved in the homocysteine-methionine cycle.
In this study, we, therefore, measured $24 \mathrm{~h}$ urinary boron excretion as a measure of boron exposure among KTR [22, 23]. We aimed to assess associations of clinical, dietary, and biochemical parameters with boron excretion. Finally, we studied prospective associations of boron excretion with mortality and graft failure among KTR.

\section{Methods}

\section{Study population and design}

We included KTR participating in the TransplantLines Food \& Nutrition Biobank and Cohort Study [24]. In brief, this prospective cohort study included 707 adult KTR approximately 1 year or longer after transplantation, with a functioning kidney allograft, who visited the outpatient clinic of the University Medical Center Groningen, Groningen, The Netherlands, between November 2008 and June 2011. All patients provided written informed consent. The study was approved by the University Medical Center Groningen institutional review board (METc 2008/186) and adheres to the Declarations of Helsinki and Istanbul (ClinicalTrials.gov: NCT02811835). In total, 693 study participants (98\%) had available $24 \mathrm{~h}$ urine samples and were included in the current analyses. No patients were lost to follow-up. A diagram visualizing the study population is presented in Figure S1. The primary endpoint of this study was all-cause mortality, and the secondary endpoint was graft failure, which was defined as re-initiation of dialysis and/or retransplantation.

\section{Clinical parameters and dietary assessment}

All measurements were performed during a morning visit to the outpatient clinic. Demographic, clinical, and transplantation-related characteristics were extracted from patient records. Diabetes was defined using the American Diabetes Association criteria [25]. Medication use and medical history were extracted from patient records, and then verified with all patients. Kidney function was assessed by means of the creatinine and cystatin C-based estimated glomerular filtration rate (eGFR), according to the CKD-EPI equation [26]. Dietary intake was assessed using a 177-item validated semi-quantitative food frequency questionnaire (FFQ) [27]. The questionnaires were self-administered, filled out at home and checked by a researcher. To assess the influence of intake of food groups, intake of fruits, vegetables, potatoes, pasta, rice, legumes, nuts, beer, wine, fish, soy products, meat products, coffee, and total plant protein intake was indexed for total energy intake. 


\section{Biochemical analyses}

Blood was drawn on the day of the study visit after a fasting period of 8 to $12 \mathrm{~h}$. Urine was collected by participants starting $24 \mathrm{~h}$ prior to the study visit, following strict instructions as previously described in detail [28]. Urinary boron concentrations were determined using inductively coupled plasma mass spectrometry (ICP-MS), as summarized in Supplementary Table 1. Plasma vitamin B6 was determined using a validated HPLC method (Waters Alliance) with fluorescence detection (FP-2020; Jasco Inc.) [29]. Other clinical chemistry assays including hemoglobin, creatinine, inflammatory parameters including high sensitivity $\mathrm{C}$-reactive protein (CRP) and leukocyte count, HDL and LDL cholesterol, triglycerides, urinary protein excretion, glucose, vitamin B12, folic acid, and homocysteine were performed using routine laboratory methods (Roche Diagnostics, Basel, Switzerland).

\section{Statistical analyses}

Baseline data of the total population, and according to tertiles of boron excretion were presented as mean \pm standard deviation, median [interquartile range (IQR)] or number (percentage) depending on the distribution. Cross-sectional univariable and adjusted linear regression analyses were performed with binary logarithmically transformed $\left(\log _{2}\right)$ $24 \mathrm{~h}$ urinary boron excretion as the dependent variable, and the previously mentioned clinical, biochemical and dietary parameters as the independent variable. Normality of the residuals was evaluated by visual inspection of Q-Q plots, where variables were transformed using a $\log _{2}$ or square root transformation if necessary to reach assumptions for linear regression.

In the next section, we performed longitudinal analyses. Kaplan Meier curves and log-rank tests were used to visualize and quantify longitudinal differences in patient survival between tertiles of urinary boron excretion. Longitudinal univariable Cox proportional hazards analyses were used to assess associations of tertiles of urinary boron excretion, and urinary boron excretion on a continuous scale with mortality. To account for potential confounding, we adjusted for known predictors of mortality among KTR and variables associated with urinary boron excretion, including age, sex, eGFR, history of cardiovascular disease, smoking status, diabetes, height, weight, LDL cholesterol, HDL cholesterol, and triglycerides. In addition, we adjusted for potential confounding by adjustment of dietary intake of fruit, nuts, fish, wine, plant protein intake and animal protein intake in multivariable Cox regression analyses to the mentioned model. In sensitivity analyses, we also adjusted for potential downstream effects of boron (i.e. plasma homocysteine, high-sensitivity C-reactive protein (hs-CRP)), and other potential confounders involved in the homocysteinemethionine cycle (i.e. vitamin B6, vitamin B12, folic acid) in additional multivariable Cox regression analyses. In further sensitivity analyses, we repeated mentioned Cox regression analyses after exclusion of patients that reported current smoking. The assumption of proportional hazards was not violated in any of the models, as assessed using Schoenfeld tests. Hazard ratios (HR) of $24 \mathrm{~h}$ urinary boron excretion were presented per doubling with $95 \%$ confidence intervals (95\% CI), and visualized to facilitate their interpretation. We assessed potential interactions of age, sex and eGFR with boron excretion in the Cox regression analyses. In secondary analyses, similar Cox proportional hazards regression analyses were performed to assess associations of boron excretion with graft failure.

For all cross-sectional analyses, the original non-imputed dataset was used, where variables with $>10$ missing values $(1.4 \%)$ are reported in the table footnotes. For all prospective analyses, multiple imputations using Fully Conditional Specification was performed using the R package 'mice', to account for missing data among variables other than data on urinary boron excretion. All data were analyzed using IBM SPSS software, version 23.0 (SPSS Inc., Chicago, IL, USA) and R version 3.5.1 (Vienna, Austria). For all analyses, P-value $<0.05$ was considered statistically significant.

\section{Results}

\section{Baseline characteristics}

Baseline characteristics are presented for the total population, and according to tertiles of $24 \mathrm{~h}$ urinary boron excretion in Table 1. We included 693 KTR with a mean \pm SD age of $53 \pm 13$ years. Median time after transplantation was 5.4 [2.0 to 12.0 ] years, and $57 \%$ of the study participants were male. Mean \pm SD eGFR at baseline was $45 \pm 19 \mathrm{ml} / \mathrm{min} / 1.73 \mathrm{~m}^{2}$. Median $24 \mathrm{~h}$ urinary boron excretion was 1275 [925 to 1729] $\mu \mathrm{g} / 24 \mathrm{~h}$. Male prevalence increased across increasing tertiles of boron excretion. Furthermore, we observed higher body weight, height, donor age, hemoglobin, and eGFR with increasing tertiles of boron excretion.

\section{Cross-sectional associations of $\mathbf{2 4} \mathrm{h}$ urinary boron excretion}

Univariable linear regression analyses showed that male sex and higher age were associated with higher urinary boron excretion (St. $\beta=0.10$ and St. $\beta=0.08$, respectively). Height, weight, and eGFR were positively associated with boron excretion, independent of age and sex (St. $\beta=0.23$, St. $\beta=0.14$ and St. $\beta=0.14$, respectively, data not shown). 
Table 1 Population characteristics at baseline in tertiles of $24 \mathrm{~h}$ urinary boron excretion

\begin{tabular}{|c|c|c|c|c|}
\hline & $\begin{array}{l}\text { Total population } \\
N=693\end{array}$ & $\begin{array}{l}\text { Tertile } 1 \\
N=231\end{array}$ & $\begin{array}{l}\text { Tertile } 2 \\
N=231\end{array}$ & $\begin{array}{l}\text { Tertile } 3 \\
N=231\end{array}$ \\
\hline Urinary boron excretion $(\mu \mathrm{g} / 24 \mathrm{~h})$ & 1275 [925-1729] & $840[695-925]$ & 1275 [1163-1389] & 2048 [1727-2600] \\
\hline \multicolumn{5}{|l|}{ Clinical characteristics } \\
\hline Male sex, $n(\%)$ & $394(56.9)$ & $117(50.6)$ & $135(58.4)$ & $142(61.5)$ \\
\hline Age, yr & $53 \pm 13$ & $53 \pm 14$ & $51 \pm 12$ & $55 \pm 12$ \\
\hline \multicolumn{5}{|l|}{ Primary renal disease, $n(\%)$} \\
\hline Unknown & $105(15.2)$ & $36(15.6)$ & $28(12.1)$ & $41(17.7)$ \\
\hline Glomerulonephritis & $181(26.1)$ & $60(26.0)$ & $61(26.4)$ & $60(26.0)$ \\
\hline Interstitial nephritis & $87(12.6)$ & $27(11.7)$ & $37(16.0)$ & $23(10.0)$ \\
\hline Cystic kidney disease & $142(20.5)$ & $43(18.6)$ & $41(17.7)$ & $58(25.1)$ \\
\hline Other congenital/hereditary disease & $38(5.5)$ & $17(7.4)$ & $15(6.5)$ & $6(2.6)$ \\
\hline Renal vascular disease & $38(5.5)$ & $12(5.2)$ & $14(6.1)$ & $12(5.2)$ \\
\hline Diabetes mellitus & $36(5.2)$ & $14(6.1)$ & $14(6.1)$ & $8(3.5)$ \\
\hline Other multisystem diseases & $48(6.9)$ & $13(5.6)$ & $17(7.4)$ & $18(7.8)$ \\
\hline Other & $18(2.6)$ & $9(3.9)$ & $4(1.7)$ & $5(2.2)$ \\
\hline Height, $\mathrm{cm}$ & $174 \pm 10$ & $171 \pm 10$ & $174 \pm 9$ & $175 \pm 9$ \\
\hline Weight, $\mathrm{kg}$ & $80 \pm 16$ & $77 \pm 16$ & $81 \pm 17$ & $83 \pm 16$ \\
\hline Body surface area, $\mathrm{m}^{2}$ & $1.94 \pm 0.22$ & $1.89 \pm 0.30$ & $1.95 \pm 0.21$ & $1.99 \pm 0.21$ \\
\hline Body mass index, $\mathrm{kg} / \mathrm{m}^{2}$ & $26.6 \pm 4.8$ & $26.4 \pm 4.9$ & $26.5 \pm 4.9$ & $27.1 \pm 4.5$ \\
\hline Systolic blood pressure, $\mathrm{mmHg}$ & $136 \pm 18$ & $136 \pm 18$ & $136 \pm 17$ & $136 \pm 18$ \\
\hline Diabetes, $n(\%)$ & $162(23.4)$ & $61(26.4)$ & $60(26.0)$ & $41(17.7)$ \\
\hline History of cardiovascular disease, $n(\%)$ & $171(24.7)$ & $49(21.2)$ & $65(28.1)$ & $57(24.7)$ \\
\hline Current smoking, $n(\%)$ & $81(12.5)$ & $32(13.9)$ & $23(11.1)$ & $26(11.7)$ \\
\hline Pre-emptive transplantation, $n(\%)$ & $106(15.3)$ & $29(12.6)$ & $40(17.3)$ & $37(16.0)$ \\
\hline Time after transplantation, $\mathrm{y}$ & $5.4[2.0-12.0]$ & $6.5[2.2-12.3]$ & $5.2[1.8-13.2]$ & $5.0[1.9-10.5]$ \\
\hline Donor age, y & $43 \pm 15$ & $42 \pm 15$ & $41 \pm 15$ & $46 \pm 16$ \\
\hline Living donor, $n(\%)$ & $234(33.8)$ & $61(26.4)$ & $79(34.2)$ & $94(40.7)$ \\
\hline \multicolumn{5}{|l|}{ Laboratory measurements } \\
\hline Hemoglobin, g/dL & $13.3 \pm 1.7$ & $12.9 \pm 1.8$ & $13.4 \pm 1.6$ & $13.5 \pm 1.8$ \\
\hline Creatinine, mg/dL & $1.4[1.1-1.8]$ & $1.6[1.1-2.0]$ & $1.4[1.1-1.8]$ & $1.4[1.1-1.7]$ \\
\hline Cystatin C, $\mu \mathrm{g} / \mathrm{dL}$ & $1.7[1.3-2.2]$ & $1.9[1.4-2.6]$ & $1.6[1.3-2.2]$ & $1.6[1.3-2.1]$ \\
\hline $\mathrm{eGFR}, \mathrm{mL} / \mathrm{min} / 1.73 \mathrm{~m}^{2}$ & $45 \pm 19$ & $42 \pm 20$ & $47 \pm 18$ & $47 \pm 17$ \\
\hline Leukocyte count, $10^{9} / \mathrm{L}$ & $8.1 \pm 2.6$ & $8.5 \pm 3.0$ & $8.2 \pm 2.4$ & $7.7 \pm 2.3$ \\
\hline HDL cholesterol, $\mathrm{mmol} / \mathrm{L}$ & $1.4 \pm 0.5$ & $1.3 \pm 0.4$ & $1.4 \pm 0.5$ & $1.5 \pm 0.5$ \\
\hline LDL cholesterol, mmol/L & $3.0 \pm 0.9$ & $3.0 \pm 1.0$ & $3.0 \pm 1.0$ & $3.0 \pm 0.9$ \\
\hline Triglycerides $\mathrm{mmol} / \mathrm{L}$ & $1.9 \pm 1.0$ & $2.0 \pm 0.9$ & $1.9 \pm 1.1$ & $1.8 \pm 1.0$ \\
\hline hs-CRP, $\mu \mathrm{g} / \mathrm{dL}$ & $1.6[0.7-4.6]$ & $1.8[0.8-5.4]$ & $1.6[0.6-4.8]$ & $1.4[0.6-3.7]$ \\
\hline Urinary protein excretion, $\mathrm{g} / 24 \mathrm{~h}$ & $0.2[0.0-0.4]$ & $0.2[0.0-0.5]$ & $0.2[0.0-0.4]$ & $0.2[0.0-0.3]$ \\
\hline Homocysteine, $\mu \mathrm{mol} / \mathrm{dL}$ & $20[16-25]$ & $22[17-27]$ & 20 [15-25] & 19 [16-23] \\
\hline Vitamin B12, pmol/L & 288 [222-377] & 296 [229-370] & $285[212-371]$ & 284 [219-388] \\
\hline Vitamin B6, nmol/L & $29[17-50]$ & $25[14-43]$ & $29[18-49]$ & $33[21-59]$ \\
\hline Folic acid, nmol/L & $18[14-26]$ & 17 [13-23] & 18 [13-25] & 20 [15-29] \\
\hline \multicolumn{5}{|l|}{ Dietary intake } \\
\hline Vegetables, grams/day & $91[54-123]$ & $91[48-112]$ & $82[56-134]$ & $91[50-135]$ \\
\hline Fruit, grams/day & $123[65-232]$ & $91[40-166]$ & $123[65-231]$ & $201[98-261]$ \\
\hline Potatoes, grams/day & $119[79-164]$ & $119[83-164]$ & $123[84-175]$ & $119[73-160]$ \\
\hline Pasta, grams/day & 19 [10-32] & $19[8-32]$ & $18[12-31]$ & $26[12-39]$ \\
\hline Rice, grams/day & $15[4-30]$ & $15[4-25]$ & $15[0-25]$ & $16[4-32]$ \\
\hline Legumes, grams/day & $4[0-11]$ & $2[0-11]$ & $2[0-11]$ & $4[0-17]$ \\
\hline Nuts, grams/day & $2[0-4]$ & $0[0-2]$ & $0[0-3]$ & $2[0-6]$ \\
\hline
\end{tabular}


Table 1 (continued)

\begin{tabular}{|c|c|c|c|c|}
\hline & $\begin{array}{l}\text { Total population } \\
N=693\end{array}$ & $\begin{array}{l}\text { Tertile } 1 \\
N=231\end{array}$ & $\begin{array}{l}\text { Tertile } 2 \\
N=231\end{array}$ & $\begin{array}{l}\text { Tertile } 3 \\
N=231\end{array}$ \\
\hline Beer, grams/day & $0[0-54]$ & $0[0-54]$ & $0[0-54]$ & $0[0-56]$ \\
\hline Wine, grams/day & $0[0-20]$ & $0[0-0]$ & $0[0-10]$ & $0[20-106]$ \\
\hline Fish, grams/day & $11[4-21]$ & $10[4-18]$ & $10[3-19]$ & $17[6-26]$ \\
\hline Soy products, grams/day & $0[0-0]$ & $0[0-0]$ & $0[0-0]$ & $0[0-0]$ \\
\hline Meat products, grams/day & $94[72-117]$ & $95[75-116]$ & $91[69-117]$ & 93 [72-119] \\
\hline Coffee, grams/day & $500[250-625]$ & $375[250-500]$ & $500[250-625]$ & $500[375-750]$ \\
\hline Total plant protein intake, grams/day & 29 [25-37] & $27[21-34]$ & $29[23-36]$ & $32[26-39]$ \\
\hline Total animal protein intake, grams/day & $48[42-54]$ & $49[39-58]$ & 49 [39-57] & $55[44-63]$ \\
\hline \multicolumn{5}{|l|}{ Medication } \\
\hline Prednisolone, $n(\%)$ & $686(99.0)$ & $227(98.3)$ & $230(99.6)$ & $229(99.1)$ \\
\hline Calcineurin inhibitor, $n(\%)$ & $397(57.3)$ & $135(58.4)$ & $133(57.6)$ & $129(55.8)$ \\
\hline Proliferation inhibitor, $n(\%)$ & $573(82.7)$ & $189(81.8)$ & $193(83.5)$ & $191(82.7)$ \\
\hline
\end{tabular}

eGFR estimated glomerular filtration rate as calculated using the creatinine and cystatin C-based CKD-EPI formula, $h s$ - $C R P$ high-sensitivity C-reactive protein

Tertile 1: boron excretion $<1040 \mu \mathrm{g} / \mathrm{day}$, tertile 2: boron excretion between 1040 and $1540 \mu \mathrm{g} / \mathrm{day}$, tertile 3: boron excretion $>1540 \mu \mathrm{g} / \mathrm{day}$. Normally distributed data are presented as mean \pm standard deviation, skewed data as median [interquartile range], and categorical data as number (valid percentage). Diabetes was defined according to the American Diabetes Association criteria [25]

Data on smoking status was missing in 46 patients (6.6\%), data on donor age was missing in 19 patients (2.7\%), data on eGFR was missing in 16 patients (2.3\%), data on hs-CRP was missing in 43 patients (5.8\%) and data on dietary intake was missing in 62 patients (8.9\%). All other variables had missing data for $<10$ patients

Higher donor age and having a living kidney donor were associated with higher boron excretion, independent of age, sex, eGFR, height and weight. In contrast, boron excretion was independently, negatively associated with hs-CRP, leukocyte count, and homocysteine.

Wine, fruit and nut consumption were the strongest dietary determinants of boron excretion (St. $\beta=0.49$, St. $\beta=0.26$, and St. $\beta=0.25$, respectively), independent of age, sex, eGFR, height and weight. Intake of fish and soy products was also independently associated with increased boron excretion, whereas intakes of potatoes and meat products were associated with lower boron excretion. In these analyses, it appeared that the positive association of age with boron intake disappeared if the association was adjusted for all the food groups that were significantly associated with urinary boron excretion (St. $\beta$ for age $=0.01,95 \%$ CI: -0.04 to 0.06$)$. Results of linear regression analyses of other clinical, dietary and biochemical parameters with urinary boron excretion are shown in Table 2.

\section{Longitudinal associations of $\mathbf{2 4} \mathrm{h}$ urinary boron excretion with all-cause mortality}

During median follow-up of 5.4 [4.8 to 6.1] years, 150 (22\%) patients died. Mortality rates among the lowest, middle, and highest tertiles of boron were 73 (32\%), 47 (20\%), and 30 (13\%), respectively $\left(P_{\text {log-rank }}<0.001\right.$, Fig. 1). Patients in tertiles 2 and 3 of boron excretion had lower risk of mortality
(HR: 0.59 , 95\% CI: 0.41 to 0.86 , and HR: 0.36 , 95\% CI: 0.24 to 0.56 , respectively) compared with patients in tertile 1 (Table 3 ). The association of tertile 3 of $24 \mathrm{~h}$ boron excretion with all-cause mortality remained, independent of potential confounders, including age, sex, eGFR, history of cardiovascular disease, smoking status, diabetes mellitus, height, weight, LDL cholesterol, HDL cholesterol, and triglycerides (HR: $0.43,95 \%$ CI: 0.27 to 0.67 ), whereas the association of tertile 2 with mortality was no longer statistically significant (HR: $0.73,95 \%$ CI: 0.50 to 1.08 ). The associations of tertile 3 of urinary boron excretion with lower risk of mortality also remained after further adjustment for the energy-indexed intake of fruit, nuts, fish, wine, plant protein and animal protein.

Cox proportional hazards analyses with $24 \mathrm{~h}$ urinary boron excretion as a continuous variable also showed strong associations with mortality, independent of adjustment for age, sex, eGFR, history of cardiovascular disease, as visualized in Fig. 2. Additional adjustment for smoking status, diabetes mellitus, height, weight, LDL cholesterol, HDL cholesterol, and triglycerides did not materially change this association (HR per doubling of boron excretion: 0.58 , 95\% CI: 0.48 to 0.76 , Table 3). Again, these associations remained fundamentally unchanged after additional adjustment for the energy-indexed intake of mentioned food groups (HR: $0.63,95 \% \mathrm{CI}$ : 0.46 to 0.86 ). We found no interactions of boron excretion with age, sex, and eGFR for the association with mortality. 
Table 2 Univariable and multivariable linear regression analysis of $\log _{2}$ urinary boron excretion $(\mu \mathrm{g} / 24 \mathrm{~h})$

\begin{tabular}{|c|c|c|c|c|}
\hline \multirow[b]{2}{*}{ Baseline variables } & \multicolumn{2}{|c|}{ Univariable } & \multicolumn{2}{|c|}{$\begin{array}{l}\text { Adj. for age, sex, eGFR, } \\
\text { height and weight }\end{array}$} \\
\hline & St. $\beta$ & $95 \% \mathrm{CI}$ & St. $\beta$ & $95 \% \mathrm{CI}$ \\
\hline \multicolumn{5}{|l|}{ Clinical characteristics } \\
\hline Female sex & -0.10 & -0.18 to -0.03 & $0.06^{*}$ & -0.04 to 0.16 \\
\hline Age at visit & 0.08 & 0.01 to 0.16 & $0.12 *$ & 0.04 to 0.19 \\
\hline Height & 0.19 & 0.11 to 0.26 & $0.20 *$ & 0.09 to 0.31 \\
\hline Weight & 0.16 & 0.09 to 0.24 & $0.09 *$ & 0.00 to 0.17 \\
\hline Body surface area & 0.20 & 0.12 to 0.27 & - & - \\
\hline Body mass index & 0.07 & -0.01 to 0.14 & - & - \\
\hline Systolic blood pressure & 0.02 & -0.05 to 0.10 & 0.00 & -0.07 to 0.08 \\
\hline Diabetes & -0.08 & -0.15 to 0.01 & -0.10 & -0.18 to -0.02 \\
\hline History of CV disease & 0.03 & -0.04 to 0.11 & 0.01 & -0.05 to 0.10 \\
\hline Current smoking & 0.00 & -0.08 to 0.07 & -0.00 & -0.08 to 0.07 \\
\hline Pre-emptive transplantation & 0.02 & -0.05 to 0.10 & 0.05 & -0.03 to 0.12 \\
\hline Time after transplantation ${ }^{1}$ & -0.02 & -0.09 to 0.06 & -0.01 & -0.08 to 0.07 \\
\hline Donor age & 0.08 & 0.01 to 0.16 & 0.12 & 0.04 to 0.19 \\
\hline Living donor & 0.14 & 0.07 to 0.21 & 0.15 & 0.07 to 0.23 \\
\hline \multicolumn{5}{|l|}{ Laboratory measurements } \\
\hline Hemoglobin & 0.18 & 0.11 to 0.25 & 0.11 & 0.02 to 0.19 \\
\hline Creatinine & -0.11 & -0.18 to -0.04 & - & \\
\hline Cystatin C & -0.20 & -0.27 to -0.12 & - & \\
\hline eGFR & 0.13 & 0.06 to 0.21 & $0.15^{*}$ & 0.08 to 0.23 \\
\hline Leukocyte count & -0.15 & 0.22 to 0.07 & -0.13 & -0.20 to -0.05 \\
\hline HDL cholesterol, $\mathrm{mmol} / \mathrm{L}$ & 0.10 & 0.02 to 0.17 & 0.13 & 0.06 to 0.21 \\
\hline LDL cholesterol, mmol/L & -0.01 & -0.09 to 0.06 & 0.00 & -0.07 to 0.08 \\
\hline Triglycerides mmol/L & -0.05 & -0.12 to 0.03 & -0.04 & -0.12 to 0.04 \\
\hline hs-CRP ${ }^{1}$ & -0.11 & -0.18 to -0.03 & -0.13 & -0.18 to -0.02 \\
\hline $24 \mathrm{~h}$ urinary protein excretion ${ }^{1}$ & -0.03 & -0.11 to 0.04 & -0.00 & -0.07 to 0.08 \\
\hline Homocysteine $^{1}$ & -0.18 & -0.26 to -0.11 & -0.16 & -0.25 to -0.07 \\
\hline Vitamin B12 1 & 0.03 & -0.05 to 0.10 & 0.03 & -0.04 to 0.10 \\
\hline Vitamin $\mathrm{B} 6^{1}$ & 0.19 & 0.12 to 0.27 & 0.20 & 0.13 to 0.27 \\
\hline Folic acid ${ }^{1}$ & 0.16 & 0.08 to 0.23 & 0.16 & 0.08 to 0.23 \\
\hline \multicolumn{5}{|l|}{$\begin{array}{l}\text { Dietary intake indexed by total } \\
\text { energy intake }\end{array}$} \\
\hline Vegetables & 0.02 & -0.05 to 0.10 & 0.04 & -0.04 to 0.12 \\
\hline Fruit $^{2}$ & 0.24 & 0.17 to 0.32 & 0.26 & 0.18 to 0.34 \\
\hline Potatoes & -0.10 & -0.17 to -0.02 & -0.13 & -0.22 to -0.60 \\
\hline Pasta & -0.02 & -0.10 to 0.06 & 0.01 & -0.07 to 0.09 \\
\hline Rice & 0.04 & -0.04 to 0.12 & 0.06 & -0.02 to 0.14 \\
\hline Legumes $^{2}$ & 0.05 & -0.03 to 0.13 & 0.04 & -0.04 to 0.12 \\
\hline Nuts $^{2}$ & 0.23 & 0.15 to 0.31 & 0.25 & 0.18 to 0.33 \\
\hline Beer $^{2}$ & 0.04 & -0.04 to 0.12 & 0.00 & -0.08 to 0.09 \\
\hline Wine $^{2}$ & 0.48 & 0.42 to 0.55 & 0.49 & 0.42 to 0.56 \\
\hline Fish $^{2}$ & 0.11 & 0.04 to 0.19 & 0.12 & 0.04 to 0.19 \\
\hline Soy products ${ }^{2}$ & 0.08 & 0.01 to 0.16 & 0.11 & 0.03 to 0.18 \\
\hline Meat products & -0.12 & -0.20 to -0.05 & -0.12 & -0.20 to -0.05 \\
\hline Coffee & 0.10 & 0.02 to 0.18 & 0.06 & -0.02 to 0.13 \\
\hline Total plant protein intake & 0.12 & 0.04 to 0.20 & 0.11 & 0.04 to 0.19 \\
\hline Total animal protein intake & 0.01 & -0.07 to 0.09 & 0.01 & -0.07 to 0.09 \\
\hline \multicolumn{5}{|l|}{ Medication use } \\
\hline Prednisolone & 0.03 & -0.05 to 0.10 & 0.03 & -0.04 to 0.10 \\
\hline
\end{tabular}


Table 2 (continued)

\begin{tabular}{llllll}
\hline & \multicolumn{2}{l}{ Univariable } & & \multicolumn{2}{l}{$\begin{array}{l}\text { Adj. for age, sex, eGFR, } \\
\text { height and weight }\end{array}$} \\
\cline { 2 - 3 } \cline { 5 - 6 } Baseline variables & St. $\beta$ & $95 \%$ CI & & St. $\beta$ & $95 \%$ CI \\
\hline Calcineurin inhibitor & -0.08 & -0.15 to -0.00 & & -0.05 & -0.13 to 0.02 \\
Proliferation inhibitor & 0.04 & -0.04 to 0.11 & & 0.02 & -0.06 to 0.09 \\
\hline
\end{tabular}

$e G F R$ estimated glomerular filtration rate as calculated using creatinine and cystatin C-based CKD-EPI formula, $h s$-CRP high-sensitivity C-reactive protein

*Regression coefficients of models which only contain age, sex, eGFR, height, and weight as independent variables. Associations of body surface area and body mass index were not multivariable adjusted because of collinearity with body weight and associations of creatinine and cystatin $\mathrm{C}$ were not multivariable adjusted because of collinearity with eGFR. Smoking status was missing in 46 patients (6.6\%), eGFR was missing in 16 patients (2.3\%) and donor age in 19 patients $(2.7 \%)$, hs-CRP was missing in 43 patients (5.8\%), vitamin B6 was missing in 11 patients (1.6\%) and data on dietary intake was missing in 62 patients $(8.9 \%)$. Other variables had missing data for $<10$ patients

${ }^{1}$ Variables were $\log _{2}$ transformed

${ }^{2}$ Variables were transformed using a square root. Diabetes was defined according to the American Diabetes Association criteria [25]

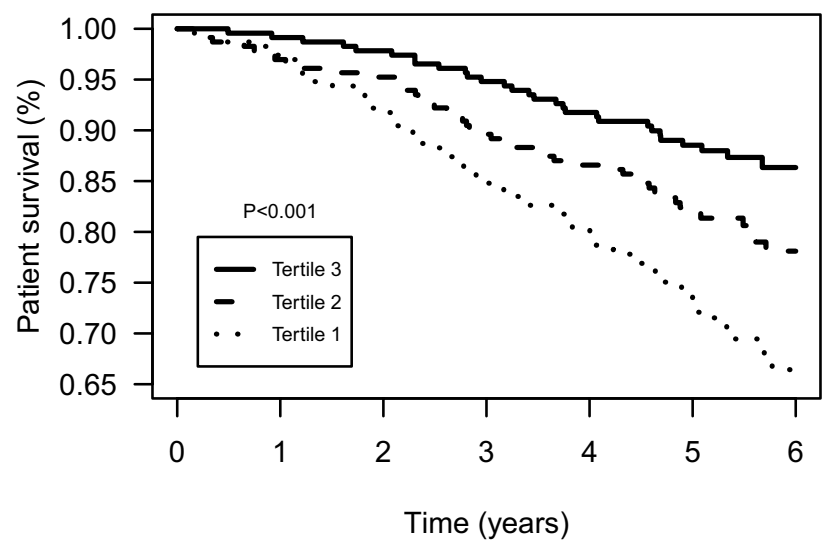

Fig. 1 Kaplan-Meier plot for all-cause mortality per tertile of $24 \mathrm{~h}$ urinary boron excretion. Tertile $1:<1040 \mu \mathrm{g} / 24 \mathrm{~h}$. Tertile 2: 1040 $1540 \mu \mathrm{g} / 24$ h. Tertile $3:>1540 \mu \mathrm{g} / 24$ h. $P$ value represents the evidence against the null hypothesis of no difference in survival across tertiles, as calculated using log-rank test.

\section{Secondary analyses with graft failure}

During a median follow-up of 5.4 [4.8 to 6.1] years, a total of $83(12 \%)$ patients experienced graft failure. Boron excretion on the continuous scale was associated with death-censored graft failure in the crude model (HR: $0.63,95 \%$ CI: 0.46 to 0.87 ), but this association was not statistically significant after adjustment for age, sex, eGFR, and history of cardiovascular disease (HR: 0.89, 95\% CI: 0.62 to 1.27 ).

\section{Sensitivity analyses}

In sensitivity analyses, we performed the Cox proportional hazards analyses including the predefined variables potentially in the causal path between boron and mortality
(Table 4). The associations of tertile 3 of boron excretion with lower risk of mortality remained materially unchanged in the full model (HR: $0.42,95 \%$ CI: 0.27 to 0.66 ). The association between boron excretion on a continuous scale and mortality also remained materially unchanged (HR per doubling of boron excretion: $0.59,95 \%$ CI: 0.46 to 0.77 ).

In further sensitivity analyses, the associations of urinary boron excretion with mortality remained materially unchanged in Cox proportional hazards analyses after exclusion of the 81 KTR reporting current smoking, as presented in Supplementary Table 2. The strong association of boron excretion with lower risk of mortality remained, independent of adjustment for age, sex, eGFR, CV history, smoking status, diabetes, height, weight, LDL and HDL cholesterol, triglycerides, and dietary intake; HR: $0.61,95 \%$ CI: 0.43 to 0.87). The analyses with adjustment for parameters potentially in the causal path also remained materially unchanged (HR: 0.56 , 95\% CI: 0.41 to 0.76 , Supplementary Table 3).

\section{Discussion}

This study is the first to assess cross-sectional and prospective associations of boron excretion in KTR. Wine, fruit and nut consumption were strongly associated with increased boron excretion. In contrast, homocysteine, hs-CRP and leukocyte count were negatively associated with boron excretion. Prospective analyses demonstrated that a higher $24 \mathrm{~h}$ urinary boron excretion, reflecting higher boron exposure [22], was independently associated with a lower risk of mortality in KTR.

Currently, no generally accepted reference values for urinary boron excretion exist. However, the observed $24 \mathrm{~h}$ urinary boron excretion rates in our study are consistent with 
Table 3 Cox regression analysis of the $24 \mathrm{~h}$ urinary boron excretion with all-cause mortality. Presented models are cumulative, and add variables to the model in each step

\begin{tabular}{|c|c|c|c|c|c|c|c|}
\hline \multirow[t]{3}{*}{ Model } & \multicolumn{5}{|c|}{ Tertiles of $24 \mathrm{~h}$ urinary boron excretion } & \multirow{2}{*}{\multicolumn{2}{|c|}{$\begin{array}{l}\text { Continuous analyses of } 24 \mathrm{~h} \\
\text { urinary boron excretion }\end{array}$}} \\
\hline & \multirow[t]{2}{*}{1} & \multicolumn{2}{|c|}{$\begin{array}{l}2 \\
1040 \text { to } 1540 \mu \mathrm{g} / \text { day }\end{array}$} & \multicolumn{2}{|l|}{$\begin{array}{l}3 \\
>1540 \mu \mathrm{g} / \text { day }\end{array}$} & & \\
\hline & & $\mathrm{HR}(95 \% \mathrm{CI})$ & $P$ value & HR $(95 \%$ CI $)$ & $P$ value & $\mathrm{HR}(95 \% \mathrm{CI})$ & $P$ value \\
\hline Univariable & Ref & $0.59(0.41-0.86)$ & 0.006 & $0.36(0.24-0.56)$ & $<0.001$ & $0.55(0.44-0.70)$ & $<0.001$ \\
\hline + age, sex, eGFR, CV history & Ref & $0.70(0.48-1.03)$ & 0.068 & $0.35(0.23-0.54)$ & $<0.001$ & $0.51(0.40-0.66)$ & $<0.001$ \\
\hline + smoking status, diabetes & Ref & $0.70(0.48-1.03)$ & 0.068 & $0.37(0.24-0.58)$ & $<0.001$ & $0.53(0.41-0.69)$ & $<0.001$ \\
\hline + height and weight & Ref & $0.72(0.49-1.06)$ & 0.093 & $0.41(0.26-0.63)$ & $<0.001$ & $0.56(0.43-0.73)$ & $<0.001$ \\
\hline $\begin{array}{l}\text { + LDL cholesterol, HDL choles- } \\
\text { terol, triglycerides }\end{array}$ & Ref & $0.73(0.50-1.08)$ & 0.1 & $0.43(0.27-0.67)$ & $<0.001$ & $0.58(0.48-0.76)$ & $<0.001$ \\
\hline+ dietary intake* & Ref & $0.77(0.52-1.14)$ & 0.2 & $0.51(0.30-0.84)$ & 0.009 & $0.63(0.46-0.86)$ & 0.004 \\
\hline
\end{tabular}

$C I$ confidence interval, $e G F R$ estimated glomerular filtration rate as calculated using creatinine and cystatin C-based CKD-EPI equation, $H R$ hazard ratio, $S D$ standard deviation

*In this model, we adjusted for age, sex, eGFR, CV history, smoking status, diabetes, LDL cholesterol, HDL cholesterol, triglycerides, and energy intake-indexed intake of fruit, nuts, fish, wine, plant protein and animal protein. Parameters of dietary intake were transformed using a square root. 150 patients (22\%) died during a median follow-up time of 5.4y [4.8-6.1y]. Addition of $\log _{2} 24 \mathrm{~h}$ urinary boron excretion significantly augmented the model of sex, age, eGFR and history of cardiovascular disease $\left(P_{\text {likelihood ratio }}<0.001\right)$. Multiple imputations was used to account for missing data in 16 cases $(2.3 \%)$ for eGFR, 46 cases $(6.6 \%)$ for smoking status, and 62 patients $(8.9 \%)$ for dietary intake. Other variables had missing data for $<10$ patients

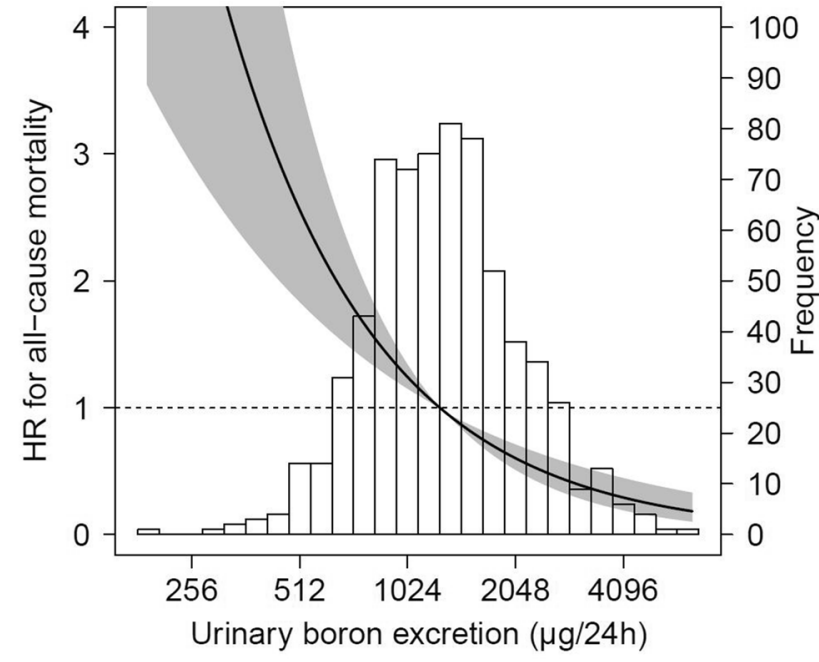

Fig. 2 Graphical representation of the association between $24 \mathrm{~h}$ urinary boron excretion and risk of all-cause mortality, based on a Cox proportional hazards regression analyses with median boron excretion $(1275 \mu \mathrm{g} / 24 \mathrm{~h})$ as reference. The model was adjusted for age, sex, eGFR, and history of cardiovascular disease, and presented in relation to the histogram of urinary boron excretion. The black line represents the hazard ratio, the grey area represents the $95 \%$ confidence interval. $H R$ hazard ratio

previous studies in Japan and the UK [30, 31]. In contrast, a population of 119 healthy subjects in Italy had higher boron excretions [32]. This difference may be explained by geographical differences, as boron concentrations are reportedly high near the Mediterranean Sea [3]. In addition, the higher boron excretion rates in the Italian study may be explained by diet, since Mediterranean diets generally include a higher intake of plant-derived foods, such as boron-rich fruit, wine and nuts, which are the current main sources of human boron ingestion [5, 6, 33]. Indeed, our results confirm the strong association of fruit and wine intake with urinary boron excretion. Dietary factors also appeared to explain the observed positive association of age with boron excretion. Other studies have also indicated that $24 \mathrm{~h}$ urinary boron excretion is a useful reflection of recent boron intake. For example, a study among 18 healthy volunteers concluded that the absorption efficiency of dietary boron intake is high [34]. Another study by Hunt and colleagues, showed that a 9.0-fold increase in oral boron intake showed a modest 1.5-fold in circulating plasma concentrations, but no signs of boron accumulation over time [35]. Both studies report that $>80 \%$ of oral boron intake was retrieved in urine, and both conclude that urinary boron excretion may provide a useful reflection of boron intake. More recently, a study has been published on the effects of the intake of mineral waters with either low, medium or high boron content on $24 \mathrm{~h}$ urinary boron excretion in humans [23]. Notably, $24 \mathrm{~h}$ urinary boron excretion strongly increased after intake of mineral water with high boron content $(3262 \pm 430 \mu \mathrm{g} / 24 \mathrm{~h}$ in the high boron group, compared to $1081 \pm 386 \mu \mathrm{g} / 24 \mathrm{~h}$ in the low boron group, respectively). The observed associations of dietary intake with boron excretion in our study further 
Table 4 Causal path analyses of the association of boron excretion with all-cause mortality. Presented models are cumulative, and add variables to the model in each step

\begin{tabular}{|c|c|c|c|c|c|c|c|}
\hline \multirow[t]{3}{*}{ Models } & \multicolumn{5}{|c|}{ Tertiles of $24 \mathrm{~h}$ urinary boron excretion } & \multirow{2}{*}{\multicolumn{2}{|c|}{$\begin{array}{l}\text { Continuous analyses of } 24 \mathrm{~h} \\
\text { urinary boron excretion }\end{array}$}} \\
\hline & \multirow[t]{2}{*}{1} & \multicolumn{2}{|c|}{$\begin{array}{l}2 \\
1040 \text { to } 1540 \mu \mathrm{g} / \text { day }\end{array}$} & \multicolumn{2}{|l|}{$\begin{array}{l}3 \\
>1540 \mu \mathrm{g} / \mathrm{day}\end{array}$} & & \\
\hline & & $\mathrm{HR}(95 \% \mathrm{CI})$ & $P$ value & HR $(95 \%$ CI $)$ & $P$ value & $\mathrm{HR}(95 \% \mathrm{CI})$ & $P$ value \\
\hline $\begin{array}{l}\text { Age, sex, eGFR, CV history, } \\
\text { smoking, diabetes, height, } \\
\text { weight }\end{array}$ & Ref & $0.72(0.49-1.06)$ & 0.093 & $0.41(0.26-0.63)$ & $<0.001$ & $0.56(0.43-0.73)$ & $<0.001$ \\
\hline+ hs-CRP ${ }^{\mathrm{a}}$ & Ref & $0.73(0.50-1.08)$ & 0.1 & $0.41(0.26-0.65)$ & $<0.001$ & $0.57(0.44-0.75)$ & $<0.001$ \\
\hline+ homocysteine $^{\mathrm{a}}$ & Ref & $0.73(0.50-1.08)$ & 0.1 & $0.42(0.27-0.66)$ & $<0.001$ & $0.58(0.44-0.75)$ & $<0.001$ \\
\hline + vitamin B6, B12, folic acid ${ }^{\mathrm{a}}$ & Ref & $0.76(0.52-1.13)$ & 0.2 & $0.42(0.27-0.66)$ & $<0.001$ & $0.59(0.46-0.77)$ & $<0.001$ \\
\hline
\end{tabular}

$C I$ confidence interval, $e G F R$ estimated glomerular filtration rate as calculated using creatinine and cystatin C-based CKD-EPI equation, $H R$ hazard ratio, $S D$ standard deviation

150 patients $(22 \%)$ died during a median follow-up time of 5.4y [4.8-6.1y]. Multiple imputations was used to account for 16 missing values (2.3\%) of eGFR, $46(6.6 \%)$ missing values for smoking status, 8 missing values (1.1\%) for vitamin B12 and folic acid, $11 \mathrm{missing}$ values (1.6\%) for vitamin B6, and 43 missing values (5.8\%) of hs-CRP

${ }^{\mathrm{a}}$ Variables were $\log _{2}$ transformed

support that $24 \mathrm{~h}$ urinary boron excretion reflects dietary boron intake.

The most important finding of this study is the strong independent association of $24 \mathrm{~h}$ urinary boron excretion with lower risk of mortality, but not graft failure. The association between higher boron excretion and lower risk of mortality may seem counterintuitive since boron used to have a reputation of being potentially harmful after several reports in the twentieth century. For example, several cases of infants with boron intoxication as a result of dipping tranquilizers in boric acid have been reported [36], and a study into the effects of preservatives indicated that ingestion of (the equivalence of) 4 to $5 \mathrm{~g}$ of borax per day may result in "loss of appetite and inability to perform work of any kind" [37]. However, the boron exposure levels in our study are two orders of magnitude lower than those described in the mentioned reports. Boron intake of up to $0.4 \mathrm{mg} / \mathrm{kg}$ body weight $(32 \mathrm{mg} /$ day for a $80 \mathrm{~kg}$ person, i.e. more than five times higher than the highest measurement in the current study) is considered safe by the WHO $[14,38]$.

The found associations of boron with lower risk of mortality are in line with geographical risk assessment studies, suggesting a decreased risk of cancer and mortality in populations with more boron exposure [17, 18]. For example, Barranco and colleagues showed that increased boron concentrations in groundwater correlated with reduced risk of prostate cancer and mortality, in a study performed in Texas, USA [17]. In a geographical risk assessment study in Northern France, Yazbeck and colleagues reported that there is a tendency toward lower mortality rates in municipalities with high boron content in drinking water [18]. Additionally, high boron exposure is an underappreciated common factor in all of the Blue Zones, further suggesting beneficial effects of boron on health and longevity. Studies in Drosophila, that showed an increased life span of 9.5\% in flies receiving low-dose boron supplementation, provide further support for the potential beneficial effects of boron on longevity [15]. The current study appears to further indicate potential beneficial effects of boron in humans, especially because the associations between higher boron excretion and decreased risk of mortality remained statistically and clinically significant, even after adjustment for multiple confounders.

Based on animal and human studies, multiple effects of boron may explain the association between higher boron excretion and lower risk of mortality. First, boron appears to play a role in the homocysteine-methionine pathway, which is involved in many biochemical reactions within the human body, including methylation of DNA, neurotransmitters, and many proteins [21, 39]. For example, a study in 2009 showed that boron deprivation increased homocysteine and decreased $S$-adenosylmethionine concentrations in rats, indicating that boron may exert part of its beneficial effects through the homocysteine-methionine pathway [21]. One may hypothesize that these findings, together with the notion that increased homocysteine and decreased $S$-adenosylmethionine concentrations are associated with many human diseases [21], may in part explain the association between boron excretion and lower risk of mortality. Although our current study cannot provide evidence for causality, the negative association between boron excretion and homocysteine further suggests the involvement of boron in the homocysteine-methionine pathway. However, the association between boron excretion and mortality was not affected by additional 
adjustment for homocysteine concentrations, which renders it unlikely that homocysteine is the major mediator in this association. The association between boron excretion and mortality was also not materially affected by adjustment for CRP and leukocyte count and by adjustment for blood lipids, also rendering it unlikely that inflammation or blood lipids were main mediators in this association.

These results suggest that boron may exert its potential beneficial effects on survival, through pathways other than the homocysteine-methionine cycle, inflammation or blood lipids. Another proposed mechanism for the beneficial effects of boron on longevity is through its binding to $\mathrm{NAD}^{+}$and cADPR, by which boron may counteract oxidative stress, and influence DNA repair, telomere stability, and ageing process [40]. Future studies are warranted to further clarify the physiological functions of boron, and assess whether this putative mechanism may indeed explain our findings. Although underlying mechanisms are only partly elucidated, the beneficial effects of boron have become increasingly clear in the past decades $[14,40]$. Since many people consistently consume less than $1 \mathrm{mg}$ boron per day, which has been suggested by the WHO as the minimal safe mean population dietary intake, boron deficiency may be a major overlooked nutritional problem worldwide $[8,33,38]$. Moreover, our study suggests beneficial effects of increasing boron intake to levels well over $1 \mathrm{mg}$ per day.

Strengths of our study are the long follow-up and the large study population. In addition, extensive data collection of many demographic, dietary and laboratory parameters enabled adjustment for many potential confounders. The primary analyses of the study concerned the association of urinary boron excretion with all-cause mortality, which is a single hypothesis to be tested, where multivariable models are applied to test robustness of the association to adjustment for potential confounders. Formally, this does not require correction for multiple testing, and we, therefore, did not correct for multiple testing in this manuscript. However, it should be mentioned that our findings concerning the primary analyses were highly significant, so that the results remained materially unchanged even if corrections for multiple testing were applied for each adjustment model. However, several limitations of this study need to be addressed. For instance, the current study was performed in the northern part of The Netherlands, which is home to a predominantly Caucasian population consuming a predominantly Dutch diet, which calls prudence to extrapolation of our results to other populations. This study should therefore be replicated in other populations, from different geographical areas, consuming different diets. To the best of our knowledge, it is unknown whether tubular boron reabsorption varies with differences in urinary boron excretion. Assessment of tubular boron reabsorption would require data on plasma boron concentrations in addition to urinary boron excretion.
Unfortunately, data on circulating boron concentrations were not available in our study. Future studies may study boron concentrations in blood, and assess tubular reabsorption rate and fractional excretion rate of boron to further clarify the underlying mechanisms of our findings. Additionally, food composition tables generally do not include information on boron content, which prevented us from comparing FFQ-based boron intake to $24 \mathrm{~h}$ urinary excretion of boron. Although several studies suggest that $24 \mathrm{~h}$ urinary boron excretion reflects intake, it remains unknown what time frame of exposure a $24 \mathrm{~h}$ urine collection might reflect, and studies that evaluated $24 \mathrm{~h}$ urinary boron excretion as a reliable and valid biomarker of intake are lacking. If our finding of an association of $24 \mathrm{~h}$ urinary boron excretion with long-term outcome would be replicated in other longitudinal cohort studies, and intervention studies would be designed, it would become increasingly relevant to generate data on reliability and validity of $24 \mathrm{~h}$ urinary boron excretion as a biomarker of intake. Another limitation is that our study population consists of patients who survived at least one year after kidney transplantation. It cannot be excluded that this introduced collider bias, which might limit extrapolation of our findings to other populations. In addition, due to its observational design, this study can only describe associations and cannot prove causality. Despite adjustment for self-reported dietary intake and circulating vitamin concentrations in blood, it is conceivable that boron excretion might be a marker of overall diet quality or consumption of plant-based foods, rather than an actual causal agent. Only randomized controlled trials can assess the potential causal effects of boron exposure on health and disease.

In conclusion, in this single-center cohort of kidney transplant recipients, we showed that high $24 \mathrm{~h}$ urinary boron excretion is associated with a lower risk of premature death, independent of potential confounders. Since $24 \mathrm{~h}$ urinary boron excretion can provide a useful reflection of daily boron exposure, these results suggest that increased boron intake may potentially decrease the risk of premature mortality in these patients. Randomized trials with dietary interventions are needed to assess the potential of increased boron intake in kidney transplant recipients.

Supplementary Information The online version contains supplementary material available at https://doi.org/10.1007/s00394-021-02702-0.

Acknowledgements The excellent technical assistance of Melanie Nebendahl is gratefully acknowledged. The TransplantLines Investigators are D. Kremer, T. J. Knobbe, J. H. Annema-de Jong, S. P. Berger, J. Blokzijl, F. A. J. A. Bodewes, M. T. de Boer, K. Damman, M. H. De Borst, A. Diepstra, G. Dijkstra, R. M. Douwes, M. F. Eisenga, M. E. Erasmus, C. T. Gan, A. W. Gomes Neto, H. Grootjans, E. Hak, M. R. Heiner-Fokkema, B. G. Hepkema, F. Klont, H. G. D. Leuvenink, W. S. Lexmond, V. E. de Meijer, H. G. M. Niesters, L. J. van Pelt, R. A. Pol, R. J. Porte, A. V. Ranchor, J. S. F. Sanders, J. C. Schutten, M. J. Siebelink, R. H. J. A. Slart, J. C. Swarte, W. Timens, D. J. Touw, 
M. C. van den Heuvel, C. van Leer-Buter, M. van Londen, E. A. M. Verschuuren, M. J. Vos, R. K. Weersma, S. J. L. Bakker: UMC Groningen Transplant Center, University Medical Center Groningen and University of Groningen, Groningen, The Netherlands.

Author contributions DK: Conceptualization, Data curation, Formal analysis, Methodology, Writing-Original draft preparation, Investigation. AP: Data curation, Formal analysis, Visualization, Writingreview \& editing. US: Resources, Investigation, Methodology, Writing-review \& editing. PH: Recourses, Investigation, Methodology, Writing - review \& editing. YvdV: Conceptualization, Writing-Original draft preparation. DG: Data curation, Formal analyses, Visualization, Writing - review \& editing. AWGN: Data curation, Investigation, Methodology, Project administration, Writing—review \& editing. TJK: Conceptualization, Writing - Original draft preparation. KL: Investigation, Formal analyses, Methodology, Recourses. MFE: Data curation, Investigation, Methodology, Project administration, Writing - review \& editing. GN: Conceptualization, Methodology, Writing-review \& editing. GR: Supervision, Conceptualization, Methodology, Writingreview \& editing. SJLB: Supervision, Conceptualization, Methodology, Writing — review \& editing, funding acquisition.

Funding The TransplantLines Food and Nutrition Biobank and Cohort Study (ClinicalTrials.gov; \#NCT02811835) was financially supported by Top Institute Food and Nutrition (grant A-1003).

Data availability Data described in the manuscript, code book, and analytic code will be made available upon request.

\section{Declarations}

Conflict of interest The authors declare no conflicts of interest.

Ethical approval All patients provided written informed consent. The study was approved by the University Medical Center Groningen institutional review board (METc 2008/186) and adheres to the Declarations of Helsinki and Istanbul (ClinicalTrials.gov: NCT02811835).

Open Access This article is licensed under a Creative Commons Attribution 4.0 International License, which permits use, sharing, adaptation, distribution and reproduction in any medium or format, as long as you give appropriate credit to the original author(s) and the source, provide a link to the Creative Commons licence, and indicate if changes were made. The images or other third party material in this article are included in the article's Creative Commons licence, unless indicated otherwise in a credit line to the material. If material is not included in the article's Creative Commons licence and your intended use is not permitted by statutory regulation or exceeds the permitted use, you will need to obtain permission directly from the copyright holder. To view a copy of this licence, visit http://creativecommons.org/licenses/by/4.0/.

\section{References}

1. Jardine AG, Gaston RS, Fellstrom BC, Holdaas H (2011) Prevention of cardiovascular disease in adult recipients of kidney transplants. Lancet 378:1419-1427. https://doi.org/10.1016/ S0140-6736(11)61334-2

2. Buettner D, Skemp S (2016) Blue zones: lessons from the world's longest lived. Am J Lifestyle Med 10:318-321. https://doi.org/10. $1177 / 1559827616637066$
3. Woods WG (1994) An introduction to boron: history, sources, uses, and chemistry. Environ Health Perspect 102:5-11. https:// doi.org/10.1289/ehp. 94102 s 75

4. OMS (2003) Boron in drinking-water background. Heal criteria other Support Inf 2:1-17

5. Naghii MR, Wall PML, Samman S (1996) The boron content of selected foods and the estimation of its daily intake among freeliving subjects. J Am Coll Nutr 15:614-619. https://doi.org/10. 1080/07315724.1996.10718638

6. Hunt CD, Shuler TR, Mullen LM (1991) Concentration of boron and other elements in human foods and personal-care products. J Am Diet Assoc 91:558-568

7. Hunt CD, Herbel JL, Idso JP (1994) Dietary boron modifies the effects of vitamin D3 nutrition on indices of energy substrate utilization and mineral metabolism in the chick. J Bone Miner Res 9:171-182. https://doi.org/10.1002/jbmr.5650090206

8. Nielsen FH (2008) Is boron nutritionally relevant? Nutr Rev 66:183-191. https://doi.org/10.1111/j.1753-4887.2008.00023.x

9. Rowe RI, Eckhert CD (1999) Boron is required for zebrafish embryogenesis. J Exp Biol 202:1649-1654

10. Fort DJ, Rogers RL, McLaughlin DW et al (2002) Impact of boron deficiency on Xenopus laevis. Biol Trace Elem Res 90:117-142

11. Lanoue L, Strong PL, Keen CL (1999) Adverse effects of a low boron environment on the preimplantation development of mouse embryos in vitro. J Trace Elem Exp Med 12:235-250. https://doi. org/10.1002/(SICI)1520-670X(1999)12:3\%3c235::AID-JTRA7\% 3e3.0.CO;2-N

12. Ralston NVC, Hunt CD (2001) Diadenosine phosphates and $\mathrm{S}$-adenosylmethionine: novel boron binding biomolecules detected by capillary electrophoresis. Biochim Biophys Acta Gen Subj 1527:20-30. https://doi.org/10.1016/S0304-4165(01) 00130-1

13. Park M, Li Q, Shcheynikov $\mathrm{N}$ et al (2004) $\mathrm{NaBC} 1$ is a ubiquitous electrogenic $\mathrm{Na}+$-coupled borate transporter essential for cellular boron homeostasis and cell growth and proliferation. Mol Cell 16:331-341. https://doi.org/10.1016/j.molcel.2004.09.030

14. Nielsen FH (2014) Update on human health effects of boron. J Trace Elem Med Biol 28:383-387. https://doi.org/10.1016/j. jtemb.2014.06.023

15. Massie HR, Whitney SJP, Aiello VR, Sternick SM (1990) Changes in boron concentration during development and ageing of Drosophila and effect of dietary boron on life span. Mech Ageing Dev 53:1-7. https://doi.org/10.1016/0047-6374(90)90029-F

16. Donoiu I, Militaru C, Obleagă O et al (2018) Effects of boroncontaining compounds on cardiovascular disease risk factors a review. J Trace Elem Med Biol 50:47-56. https://doi.org/10. 1016/j.jtemb.2018.06.003

17. Barranco WT, Hudak PF, Eckhert CD (2007) Evaluation of ecological and in vitro effects of boron on prostate cancer risk (United States). Cancer Causes Control 18:71-77. https://doi.org/10.1007/ s10552-006-0077-8

18. Yazbeck C, Kloppmann W, Cottier R et al (2005) Health impact evaluation of boron in drinking water: a geographical risk assessment in Northern France. Environ Geochem Health 27:419-427. https://doi.org/10.1007/s10653-005-1796-6

19. Rogoveanu OC, Mogoşanu GD, Bejenaru C et al (2015) Effects of calcium fructoborate on levels of C-reactive protein, total cholesterol, low-density lipoprotein, triglycerides, IL-1 $\beta$, IL-6, and MCP-1: a double-blind, Placebo-controlled Clinical Study. Biol Trace Elem Res 163:124-131. https://doi.org/10.1007/ s12011-014-0155-9

20. Scorei RI, Rotaru P (2011) Calcium fructoborate-potential antiinflammatory agent. Biol Trace Elem Res 143:1223-1238. https:// doi.org/10.1007/s12011-011-8972-6

21. Nielsen FH (2009) Boron deprivation decreases liver S-adenosylmethionine and spermidine and increases plasma homocysteine 
and cysteine in rats. J Trace Elem Med Biol 23:204-213. https:// doi.org/10.1016/j.jtemb.2009.03.001

22. Jansen JA, Andersen J, Schou JS (1984) Boric acid single dose pharmacokinetics after intravenous administration to man. Arch Toxicol 55:64-67. https://doi.org/10.1201/b17486

23. Seidel U, Haegele FA, Baumhof E et al (2021) Boron contents of German mineral and medicinal waters and their bioavailability in drosophila melanogaster and humans. Mol Nutr Food Res. https:// doi.org/10.1002/MNFR.202100345

24. Van Den Berg E, Engberink MF, Brink EJ et al (2013) Dietary protein, blood pressure and renal function in renal transplant recipients. Br J Nutr 109:1463-1470. https://doi.org/10.1017/ S0007114512003455

25. American Diabetes Association (2017) Standards of medical care in diabetes. Diabetes Care 40:S11-S24

26. Inker LA, Schmid CH, Tighiouart $\mathrm{H}$ et al (2012) Estimating glomerular filtration rate from serum creatinine and cystatin C. N Engl J Med 367:20-29. https://doi.org/10.1056/NEJMoa1114248

27. Feunekes GI, Van Staveren WA, De Vries JH, Hautvast JG (1993) Relative and biomarker-based validity of a food-frequency questionnaire estimating intake of fats and cholesterol. Am J Clin Nutr 58:489-496

28. Klont F, Kremer D, Gomes Neto AW et al (2021) Metabolomics data complemented drug use information in epidemiological databases: pilot study of potential kidney donors. J Clin Epidemiol 135:10-16. https://doi.org/10.1016/j.jclinepi.2021.02.008

29. Talwar D, Quasim T, McMillan DC et al (2003) Optimisation and validation of a sensitive high-performance liquid chromatography assay for routine measurement of pyridoxal 5-phosphate in human plasma and red cells using pre-column semicarbazide derivatisation. J Chromatogr B Anal Technol Biomed Life Sci 792:333-343. https://doi.org/10.1016/S1570-0232(03)00320-9

30. Imbus HR, Cholak J, Miller LH, Sterling T (1963) Boron, cadmium, chromium, and nickel in blood and urine. Arch Environ Heal An Int J 6:286-295. https://doi.org/10.1080/00039896.1963. 10663391

31. Usuda K, Kono K, Dote T et al (1998) Study on urine boron reference values of Japanese men: use of confidence intervals as an indicator of exposure to boron compounds. Sci Total Environ 220:45-53. https://doi.org/10.1016/S0048-9697(98)00243-5

32. Minoia C, Sabbioni E, Apostoli P et al (1990) Trace element reference values in tissues from inhabitants of the European community I. A study of 46 elements in urine, blood and serum of Italian subjects. Sci Total Environ 95:89-105. https://doi.org/10. 1016/0048-9697(90)90055-Y

33. Rainey C, Nyquist L (1998) Multicountry estimation of dietary Boron intake. Biol Trace Elem Res 66:79-86. https://doi.org/10. 1007/BF02783128

34. Naghii MR, Samman S (1997) The effect of boron supplementation on its urinary excretion and selected cardiovascular risk factors in healthy male subjects. Biol Trace Elem Res 56:273-286. https://doi.org/10.1007/BF02785299

35. Hunt CD, Herbel JL, Nielsen FH (1997) Metabolic responses of postmenopausal women to supplemental dietary boron and aluminum during usual and low magnesium intake: boron, calcium, and magnesium absorption and retention and blood mineral concentrations. Am J Clin Nutr 65:803-813. https://doi.org/10.1093/ AJCN/65.3.803

36. Valdes-Dapena MA, Arey JB (1962) Boric acid poisoning. J Pediatr 61:531-546. https://doi.org/10.1097/00007611-19411 2000-00018

37. Wiley HW (1904) Influence of food preservatives and artificial colors on digestion and health. I. Boric acid and borax. US Dep Agric Bull No 84, Pt 1. https://archive.org/details/influenceoffood p84wile

38. World Health Organization (1996) Trace elements in human nutrition and health. 175-179

39. Loenen WAM (2006) S-Adenosylmethionine: Jack of all trades and master of everything? Biochem Soc Trans 34:330-333. https://doi.org/10.1042/BST20060330

40. Nielsen FH (2018) Boron in aging and longevity. In: Malavolta M, Mocchegiani E (eds) Trace elements and minerals in health and longevity. Springer International Publishing, Cham, p 332 